TITLE:

\title{
ECOLOGY AND BIOLOGICAL PRODUCTION OF LAKE NAKA-UMI AND ADJACENT REGIONS -1. GENERAL INTRODUCTION-
}

\section{$\operatorname{AUTHOR}(\mathrm{S}):$}

Miyadi, Denzaburo; Kawanabe, Hiroya; Harada, Eiji

\section{CITATION:}

Miyadi, Denzaburo ...[et al]. ECOLOGY AND BIOLOGICAL PRODUCTION OF LAKE NAKA-UMI AND ADJACENT REGIONS -1. GENERAL INTRODUCTION-. SPECIAL PUBLICATIONS FROM THE SETO MARINE BIOLOGICAL LABORATORY 1964, 2(1): 1-7

\section{ISSUE DATE:}

1964-12

URL:

http://hdl.handle.net/2433/176451

RIGHT: 


\title{
ECOLOGY AND BIOLOGICAL PRODUCTION OF LAKE NAKA-UMI AND ADJACENT REGIONS
}

\section{GENERAL INTRODUCTION ${ }^{1)}$}

\author{
DenZABURo MIYADI ${ }^{2>}$ \\ Seto Marine Biological Laboratory and \\ Zoological Institute, Kyoto University \\ HiROYA KAWANABE \\ Zoological Institute, Kyoto University \\ and \\ EIJI HARADA ${ }^{33}$ \\ Zoological Institute, Kyoto University
}

With Plate I and 1 Text-figure

\begin{abstract}
Along the coast of the Japan Sea are found many brackish ponds and lakes, which are separated from the sea mostly by sandbars or dunes. Lake Naka-umi is one of the largest of these lakes. It is located on the border of the Shimane and the Tottori Prefecture, and is in a peculiar situation in that it is the intermediate expansion from a freshwater lake, Lake Shinji-ko, to a marine bay, Miho Bay, leading to these on opposite ends through narrow channels. Since the warm water of high salinity of the Tsushima Current reaches well into Miho Bay, since the tidal range in the Japan Sea is small and rarely exceeds 0.4 meters, and since a fairly good quantity of freshwater is conveyed into Lake Shinji-ko, and Lake Naka-umi as well, by several large rivers, differences in physical and chemical features between these waters are in most cases rather abrupt, and fluctuations of them are at times astounding in Lake Naka-umi. This bestows the areas particular biotas and, accordingly, varying influences upon life of organisms themselves, seasonally or at different stages of growth.

Such a region of brackish water is, generally speaking, one of the most productive areas-both in the biological and the economic sense. Various fisheries depending on the particular biology of sea-food organisms and on

1) Contributions from the Seto Marine Biological Laboratory, No. 429.

2) Present address: Japan Monkey Center, Inuyama, Gifu-ken.

3) Present address: Biological Laboratory, Yoshida College, Kyoto University, Yoshida, Sakyô-ku, Kyoto.
\end{abstract}


local hydrology and topography of the region have been developed. Mulet fishery of Lake Naka-umi renders successful catches during a short period when the fish gathers into there in its younger years in a favourable seasons. The shrimps and mysids migrate and aggregate in numbers in certain areas. Spat collecting of oysters and Anadara is severely dependant on hydrographic conditions. Some migratory fishes from offshore make the interrelations much more complicated. Fluctuations of sea-weeds grow th have been well noticed, which in turn have affected the living natural resources and conditions for certain fisheries. Thus, it has been a great concern of fishermen, and of fishery biologists, to understand how the natural stocks of sea-food animals and weeds within the region are sustained, increased or diminished. Not only to find practical measure of fisheries management, but to arrive at any recognition of fish population dynamics and biological production have also been an underlying intension of biologists. Therefore, the system of waters concerned, two lakes and a bay, has attracted interests of many fishery biologists, limnologists and oceanographers.

As is generally admitted, however, organisms in an area are so closely interrelated and none of them could practically be isolated in nature even for elucidation of its biology. The whole body of inhabitants influencing each other in an area for certain period of time is a unit, a biological community, that have its own structure regulating interrelations, population fluctuations, biological production, and dynamics of life, of its members. Needless to say, the fundamental picture of the community structure or of ecosystem is similar, but perhaps the differences in species composition may bring into different food-relations and different rates of production and consumption for equivalent or parallel organisms. The amounts and roles to be played by certain organisms, for example, sea-weeds, nannoplankton or migratory fishes, are different. These result in different structures of production system.

As we consider the ecological whole as above, we must, consequently, hold in mind precise image of what each member is. A number of organisms found in each lake or bay of the region of Lake Naka-umi stay there only during a part of their life-cycle and move to other or outside at other time. Still, as far as they are in an area, they inevitably enter into the complex processes of a biotic community. The reciprocal relations might be regarded temporal, but is there any area that has no trace of these? It is often this property that importantly interlaces the communities in the sea. For this reason, the study of the mode of life of organisms makes a center of ecological survey. The objective of the present investigation lies just at this point-to explore how the dynamics of natural population and biological production are shadowed by the lives of members of a community.

However productive biologically the region may be, sometimes the society 
stays no longer to care for that. Once flourished in the ancient time the trading ports on the Japan Sea coast, but modern industries have been concentrated on the Pacific coast. Lately, the backwardness of the northern side of Japan started to be argued among people there and to set up new industrial areas has been discussed. Besides, as a result of unlimited improvement of city life and of development in industrial production, freshwater is becoming a new critical natural resource. Lake Hachirô-gata, formerly brackish, have nearly been converted into the reclaim land and freshwater reservoir for industry and irrigation use. Another example is Kojima Bay in the Seto Inland Sea and this has shown a switch over from marine to freshwater fishery. People living around the district would be benefitted and saved from flood or salt pollution if the water is thus properly controlled. On the contrary, the fishermen who are now entitled to a share of natural resources of lakes would have to risk to continue fishing on surviving or possibly promissing resources, or to seek other jobs for living. The undertaking would perhaps evict some of them from the area. Navigation and some ports will fall down. These different interests should, however, be compromised notwithstanding the project is carried out or not. And for the threatened people must be afforded proper compensation and support, financially or in other way, of short or long term. Careful consideration on how the biological production of the areas will be afterwards is indispensable for the achievement of the project.

Under these situations the Shimane Prefectural Government initiated the examination of the possibility and productiveness in social sense of that Lake Naka-umi be made over into a freshwater lake and that a part of it be converted into reclaim land. In connection with this project they decided to take up biological and fishery survey of the region, and this was suggested to us. The biological investigation of an area in its purely academic sense should involve much wider prospect. But we devised and concentrated our study primarily to meet their request, namely ecology and biological production. The investigation was set off in October 1958 and it continued until March 1962 with financial support from the Prefectural Government. Materials and data gained have been partly examined and arranged for publication, but still a lot of them are under examination. The present paper is a brief sketch of the investigation and an introduction to the reports which will be published separately when they are ready.

\section{General Features of the Region}

Translation of Japanese names of places into foreign languages is ever nuisance and often causes confusion and misunderstanding, since these translations are conventional and are not discriminated strictly on the scientific basis of 
geography or so. In the present series, therefore, we follow, avoiding niggling dispute, the designations proposed by the Limnological Society of Japan.

Lake Shinji-ko is located at the uppermost part of this water system, to cover an area of $81.7 \mathrm{~km}^{2}$ with an average depth of $4 \mathrm{~m}$ and a maximum depth of $5.2 \mathrm{~m}$. It is weakly saline, the chlorinity varying from 0.58 to $3.00 \%$ at the surface layer, and from 0.60 to $6.71 \%$ at the bottom. The water is almost saturated with oxygen throughout the year, but in the summer season the oxygen content sometimes falls down to as low as 25 to $30 \%$ in the deepest part.

Lake Naka-umi is situated between Lake Shinji-ko and Miho Bay, being connected with the former by River Ôhashi-gawa and with the latter by the Sakai Channel. It has an area of $99.2 \mathrm{~km}^{2}$, and its floor is generally flat, the average depth being $5.6 \mathrm{~m}$ and the maximum $7.5 \mathrm{~m}$. It is a strongly brackish region, and surface chlorinities are mostly between 6.30 and $13.12 \%$, while the values for bottom water are in the range 11.71-17.76\%. The amounts of dissolved oxygen at the bottom layer fluctuate greatly according to season; namely, the oxygen content rises to $70 \%$ or more in winter, and is reduced in summer to about $10 \%$ or less in the southern part and to $50 \%$ or more in the northern part where the depth is smaller and the water is better replenished by the tidal influence. The values for surface water are $80 \%$ or more throughout the year.

Miho Bay, about $112.4 \mathrm{~km}^{2}$ in area, is extending on the east side of the Shimane Peninsula to receive waters flowing down this water system. The Bay is fully exposed to the east and north, and depths increase progressively to a maximum of $35 \mathrm{~m}$ at the mouth, the average being $20 \mathrm{~m}$. The chlorinity stays rather unchanged around 18\% throughout the year, but it may fall down to $15 \%$ on the surface near the outlet of the Sakai Channel. Dissolved oxygen content in the water amounts to $90 \%$ or more throughout the year both at the surface and at the bottom layer.

\section{Methods of Investigation}

\section{Chemical and Physical Conditions of the Region}

At each time of collection observations were taken on the sea for weather and air temperature, wave and swell, water colour and transparency, and depth of water. For the samples of water taken from standard depths temperature and $\mathrm{pH}$ were also measured on the sea. The parts of water samples were brought back to the laboratory and were rendered for the analyses of chlorinity, dissolved oxygen content, contents of phosphate, total phosphorus, ammonium salts, nitrite, total nitrogen, silicate and total carbonate, and consumption amounts of potassium permanganate and iodine, by following the 
Ecology and Biological Production of Lake Naka-umi and Adjacent Regions, 1

current standard procedures of analysis. Temperature and nature of the bottom substrate were recorded.

\section{Primary Producers}

Net phytoplankters were collected with a cone net of a cloth of about 230 meshes to an inch and with the YAMAZI's automatic plankton sampler with the same filtering gauze set inside. The species composition, standing crop in weight and in amount of chlorophyll, and the rate of production (by oxygen consumption method and ${ }^{14} \mathrm{C}$ method) were examined. Nannoplankters were settled and collected from the water pumped up and filtered beforehand through the gauze of the cone net, and were subsequently examined.

Samples of larger weeds and rooted aquatic plants were obtained by clearing the unit areas and were made for examination in the same ways.

\section{Secondary Producers}

Zooplankers were collected with a cone net of the gauze of 72 meshes to an inch and with the YAMAZI's automatic plankton sampler using the same filtering gauze. The species composition and standing crop in volume were examined.

Phytal animals were washed out and collected from weeds which were taken up from the unit areas by using a square basket. The species composition and standing crop in weight were recorded.

Benthic animals were caught by the Ekman-Birge bottom sampler and by a small drag net, and they were also rendered for the same examination.

\section{Tertiary Producers}

Larger carnivores such as fishes, shrimps, crabs, squids and octopi were captured and collected by various devices as quantitatively as possible. Such gears used were a large cone net (mouth diameter of $1 \mathrm{~m}$, about 35 meshes to an inch), a medium-size cone net (mouth diameter of $50 \mathrm{~cm}$, about 40 meshes to an inch), smaller drag nets, a small beam trawl, a dragging coracle net called "Genshiki-ami", a filtering set net called "Kobukuro-ami", a large square set net called "Masu-ami", a stab net, hand nets and angling. The catches were counted by species and measurements of length and weight were taken from each individual if the species did not number too many in a sample. Stomach contents of them were examined in detail as far as possible.

Observations on some fishes and other animals were often made underwater by using a scuba, and sometimes under favourable condition they were traced on the echo-sounder.

Materials obtained regularly from fishery markets in and near the region were regarded to afford knowledges of great value particularly on larger fishes. Daily or monthly chronicles of catches were completed by about fifty fishermen, 
and much information on the the fishery industry around the district and experiences of fishing were intentionally gathered from fishermen, which were sometimes highly useful.

\section{Collaborating Members}

Members engaged in the present survey were as follows. The institutions to which these members are indicated to belong are those at the time of the survey.

MryaDI, Denzaburo, Seto Marine Biological Laboratory and Zoological Institute,

Kyoto University.

MORI, Syuiti, Zoological Institute, Kyoto University.

KaWANABE, Hiroya, Zoological Institute, Kyoto University.

HARADA, Eiji, Zoological Institute, Kyoto University.

Takamatsu, Shiro, Zoological Institute, Kyoto University.

MAKI, Iwao, Zoological Institute, Kyoto University.

Sunaga, Tetsuo, Zoological Institute, Kyoto University.

Azuma, Mikio, Zoological Institute, Kyoto University.

SAITo, Yoko Tezuka, Zoological Institute, Kyoto University.

NEGORO, Ken-ichiro, Otsu Hydrobiological Station, Kyoto University.

YAMAZI, Isamu, Seto Marine Biological Laboratory, Kyoto University.

Fuse, Shin-ichiro, Seto Marine Biological Laboratory, Kyoto University.

IwaI, Tamotsu, Fisheries Institute, Kyoto University.

Asano, Hirotoshi, Fisheries Institute, Kyoto University.

SAIJO, Yatsuka, Water Research Laboratory, Nagoya University.

SAKAMOTO, Mitsuru, Water Research Laboratory, Nagoya University.

ONDO, Yoshinori, Biological Institute, Tottori University.

HABE, Tadashige, Amakusa Marine Biological Laboratory, Kyushu University. KIKUCHI, Taiji, Biological Institute, Kyushu University.

Acknowledgements. This series of reports are published with the financial aid from the Seto Marine Biological Laboratory, for which we are most grateful to the authorities of the Laboratory. The present investigation was carried out with the help of the Construction Office of Naka-umi Reclaim Land of the Shimane Prefectural Government. We wish to express our thanks to the personnels of the Office for their kind cooperation in various parts of the survey during the whole course of the investigation. We are also indebted to the following persons for their kind aids: the people of the fishery cooperative associations around Lake Shinji-ko, Lake Naka-umi and Miho Bay, Mr. H. Okabayashi of the Public Health Station of the Shimane Prefecture, and the staff of the Sakai Branch of the Tottori Fisheries Experimental Station. 
Ecology and Biological Production of Lake Naka-umi and Adjacent Regions, 1

\section{EXPLANATION OF PLATE I}

Figure 1. A view of Lake Naka-umi and Miho Bay on its left further back, looking eastward.

Figure 2. A view of Lake Shinji-ko, looking westward.

Figure 3. A fishery boat of yotsude-ami on Lake Shinji-ko.

All photographs are taken by Mr. Chiaki YAMAGuchi of Matsue. 
Plate I
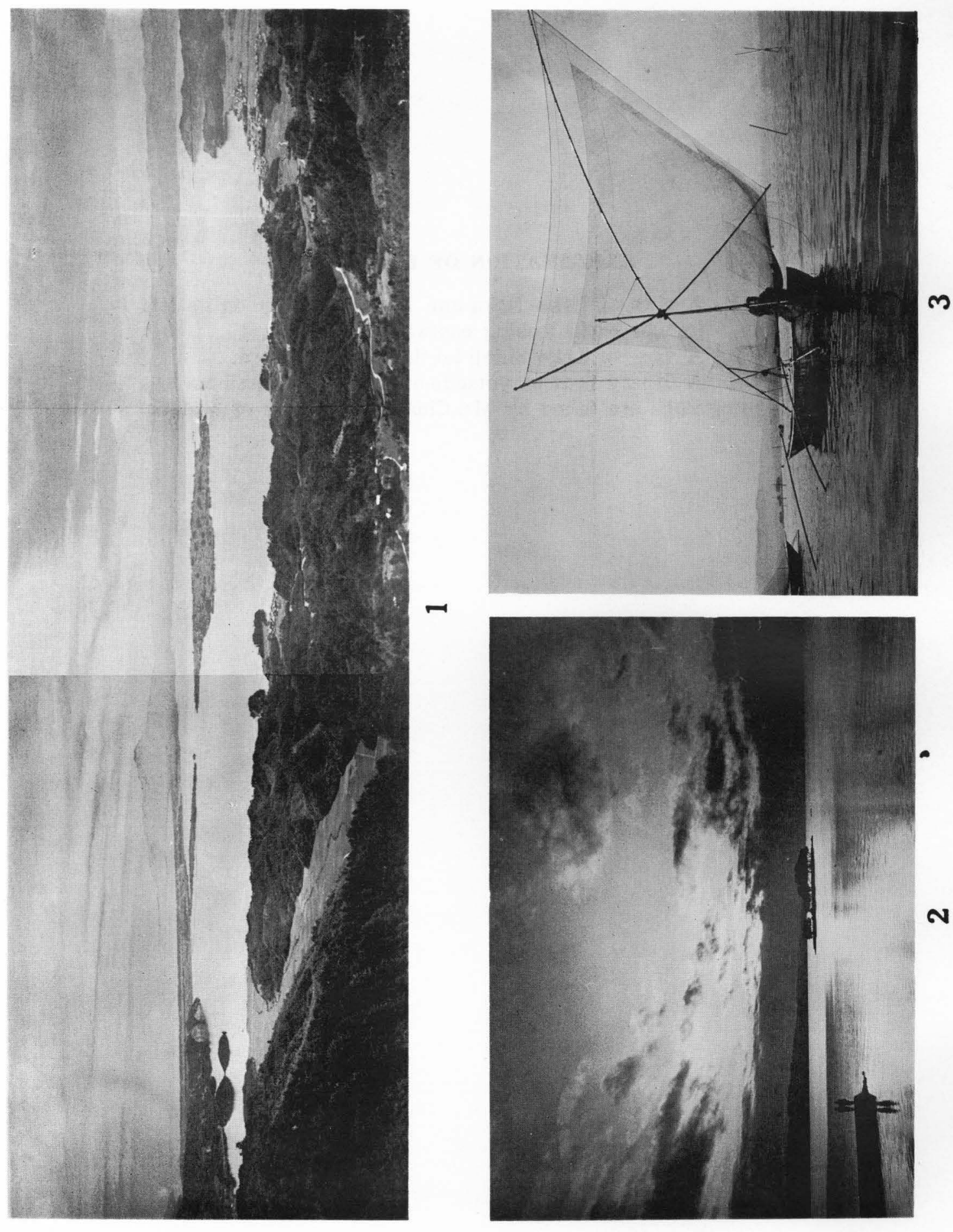

N 